\title{
Deutsche Röntgengesellschaft schließt sich einer Initiative des British Institute of Radiology an
}

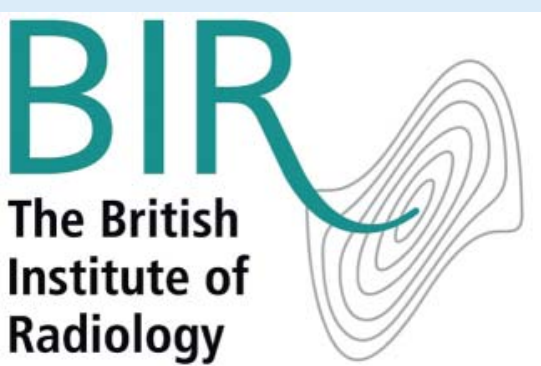

Die Deutsche Röntgengesellschaft (DRG) hat sich mit dem British Institute of Radiology (BIR) und weiteren radiologischen Gesellschaften weltweit in einer neuen Initiative zusammengeschlossen: Dem BIR World Partner Network. In dieser internationalen Gemeinschaft radiologischer Gesellschaften geht es um das gemeinsame Ziel, das Wissen und das Verständnis von radiologischer Bildgebung bei Radiologen, medizinisch-technischen Assistenten und Medizinphysikern weltweit zu fördern.

Die Mitglieder aller Gesellschaften erhalten regelmäßig informative Fachinhalte, die online abgerufen werden können. Hierzu gehören beispielsweise Paper aus dem British Journal of Radiology sowie der Zugang zu Webinaren mit international renommierten Medizinern und Videoinhalten weltweit anerkannter Experten.

Die Inhalte werden allen DRG-Mitgliedern mit dem monatlichen DRG-Newsletter zur Verfügung gestellt.

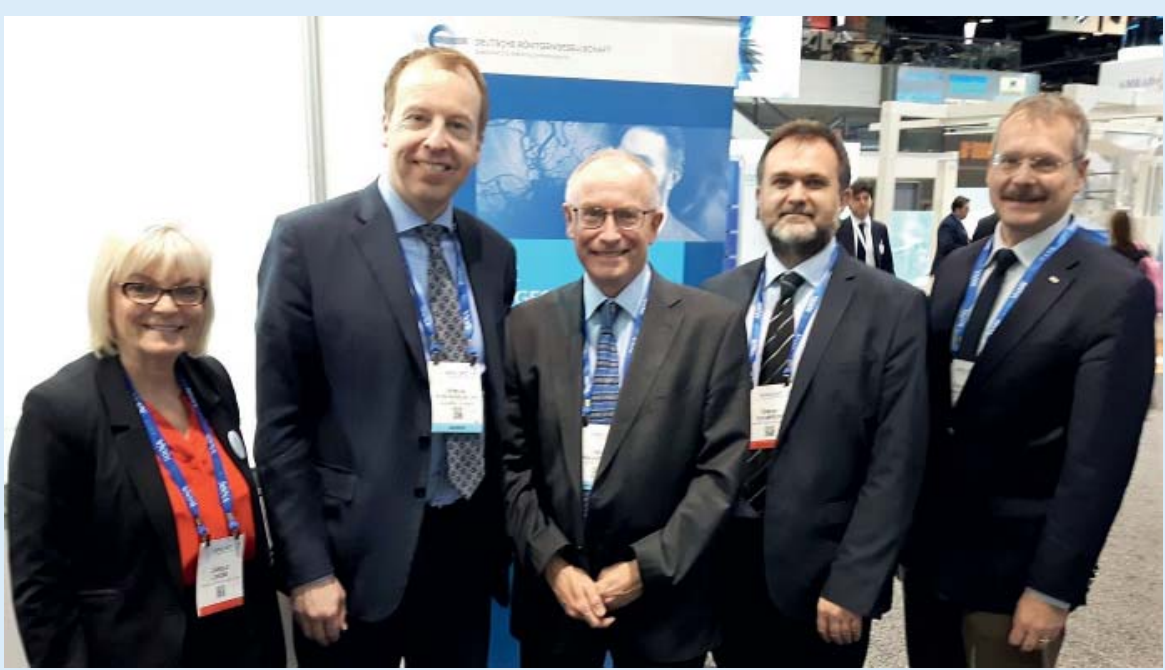

Prof. Dr. Stefan Schönberg, Präsident der Deutschen Röntgengesellschaft: „Wir freuen uns, mit dem BIR einen renommierten Partner gewonnen zu haben, der uns hilft, unsere Mitglieder auf dem neuesten Stand zu halten. Es ist eine Ehre, Teil eines solch starken internationalen radiologischen Netzwerkes zu sein.“

Andy Rogers, Präsident des BIR, ergänzt: „Wir freuen uns sehr, die Deutsche Röntgengesellschaft und andere führende Gesellschaften aus der ganzen Welt zusammenschließen zu können, um Wissen und Expertise auszutauschen. Im Endeffekt wird dies Patienten überall zugutekommen."
TEILNEHMENDE GESELLSCHAFTEN

- Sociedad Argentina de Radiología

- Federacion Argentina de Radiologia

- Australian Society of Medical Imaging and Radiation Therapy

- Brazilian College of Radiology and Diagnostic Imaging

- Canadian Association of Medical Radiation Technicians

- Chinese Society of Radiology

- Chinese Taipei Society of Radiology

- Deutsche Röntgengesellschaft

- Hong Kong College of Radiology

- Indian Radiological and Imaging Association

- International Society of Radiographers and Radiological Technologists

- Israel Radiological Society

- Japanese Radiological Society

- Russian Society of Radiology

- Spanish Radiological Society

- Radiological Society of South Africa 